\title{
Leptin actions on the reproductive neuroendocrine axis in sheep
}

\author{
C. L. Adam ${ }^{1}$, Z. A. Archer ${ }^{1}$ and D. W. Miller ${ }^{2}$
}

\begin{abstract}
'Molecular Neuroendocrinology Group, Appetite and Energy Balance Division, Aberdeen Centre for Energy Balance and Obesity, Rowett Research Institute, Bucksburn, Aberdeen AB21 9SB, UK; and ${ }^{2}$ Department of Agriculture and Forestry, Aberdeen Centre for Energy Regulation and

Obesity, University of Aberdeen, Aberdeen AB24 5UA, UK
\end{abstract}

\begin{abstract}
There is a growing literature on the role of leptin in appetite and neuroendocrine regulation in domestic ruminants. Circulating leptin concentration is higher in fat than in thin sheep, is reduced by chronic underfeeding and is higher in sheep subjected to long-day rather than short-day photoperiods. Leptin is reduced acutely by fasting and increases after meals so that there are long-and short-term components to the systemic leptin signal. Nutritional stimulation of reproductive neuroendocrine output is associated with increased circulating concentrations of leptin; peripheral leptin administration restores $\mathrm{LH}$ secretion in fasted sheep, and leptin is permissive (although not a trigger) for puberty. Intracerebroventricular (i.c.v.) pharmacological leptin infusion stimulates LH in underfed but not in well-fed sheep, and reduces food intake in well-fed sheep. A single i.c.v. pharmacological injection or physiological infusion of leptin stimulates LH in well-fed sheep, with or without a concomitant decrease in appetite. Furthermore, these appetite and $\mathrm{LH}$ responses are differentially affected by photoperiod, indicating that different neuronal pathways may mediate the two responses. Hypothalamic leptin receptors co-localize with orexigenic and anorexigenic neurones, some of which contact GnRH cells, but the confluence of leptin signalling with photoperiod (melatonin) signalling remains unresolved. Photoperiod-entrained sheep provide potential models of altered central leptin sensitivity, in which downstream mechanisms regulating appetite and $\mathrm{GnRH}$ may be dissociated.
\end{abstract}

\section{Introduction}

It is now accepted dogma across the species that circulating leptin is broadly sensitive to nutritional status, and that leptin acts on target sites within the hypothalamus to modify appetite and energy balance (Ahima et al., 2000). Leptin was discovered as the gene product deficient in obese $o b / o b$ mutant mice and has since revolutionized clinical obesity research. These mutants are not only obese, but also express multiple neuroendocrine disorders and 
are infertile. As leptin restores fertility to $o b / o b$ mice, its actions as a metabolic signal to the reproductive axis have also received attention. Although early studies on leptin were originally conducted in laboratory rodent species, it was recognized at the last symposium in this series that leptin could be playing a key role in nutritional modulation of reproduction in domestic ruminants (Keisler et al., 1998). Subsequently, there have been many reports on leptin secretion and actions in farm animal species. The purpose of this review is to assess recent evidence from studies with sheep for the feedback role of leptin in reproductive neuroendocrine regulation.

\section{Leptin expression and the systemic leptin signal}

Partial cloning of genes for ovine leptin (Dyer et al., 1997a) and the signalling form of the ovine leptin receptor (OB-Rb; Dyer et al., 1997b) allowed initial investigations of gene expression for the leptin system in sheep. However, studies on the biology of leptin in domestic ruminants were hampered by the lack of homologous assays to measure circulating leptin concentrations. Initial estimates using a commercial 'multi-species' radioimmunoassay designed to measure human leptin were not validated and were subsequently found to underestimate plasma leptin in sheep and cattle (Ehrhardt et al., 2000; Chilliard et al., 2001), despite the close similarity between human and ruminant leptin in terms of amino acid sequence (Dyer et al., 1997a). Once biologically active recombinant ovine and bovine leptins were available and antibodies could be raised against them, homologous immunoassays could be developed. Several radioimmunoassays have been validated, all within the last two years, providing the necessary breakthrough to allow characterization of the systemic leptin signal in sheep (Blache et al., 2000a; Delavaud et al., 2000; Ehrhardt et al., 2000; Marie et al., 2001).

Leptin is produced mainly in white adipose tissue in domestic ruminants and is secreted into circulating blood at concentrations influenced by genetic, nutritional, physiological and environmental factors (for a review, see Chilliard et al., 2001). Both gene expression and circulating plasma leptin concentrations are reduced in sheep by undernutrition (Bocquier et al., 1998; Blache et al., 2000a; Délavaud et al,, 2000; Marie et al., 2001) and fasting (Marie et al., 2001; Adam et al., 2002; Daniel et al., 2002). An additional effect of photoperiod has been reported in sheep, with higher leptin secretion in sheep subjected to long-day as opposed to short-day photoperiods (Bocquier et al., 1998; Marie et al., 2001) (Fig. 1). However, this is likely to reflect photoperiod-driven changes in intake and adiposity, as food restriction in long days reduces leptin concentrations to approximately short-day values (Marie et al., 2001), and melatonin administration has no effect on plasma leptin concentrations in ewes subjected to long day photoperiods (Delavaud et al., 2002).

Sexual dimorphism in circulating leptin is reported for sheep: males have consistently lower values than females, in common with other species. Thus, prepubertal ewe lambs have higher plasma leptin concentrations than age and nutritionally matched ram lambs (Ehrhardt et al., 2000); and adult ewes in the study of Blache et al. (2000a) had higher values than both intact and castrated rams. However, in both sexes leptin is similarly influenced by plane of nutrition and adiposity (Blache et al., 2000a; Ehrhardt et al., 2000).

Although plasma concentrations of leptin are positively correlated with adiposity in sheep (Blache et al., 2000a; Daniel et al., 2002), there are additional short-term factors that can have an acute effect irrespective of adiposity. For example, fasting reduces plasma leptin to basal values in sheep within $24 \mathrm{~h}$ and low amplitude post-prandial concentration peaks are observed (Fig. 1; Marie et al., 2001). Furthermore, high food intake is associated with high circulating leptin, and an increase in intake in relatively thin sheep increases plasma leptin before any increase in adiposity (Archer et al., 2002a). It therefore appears that leptin does 
(a)

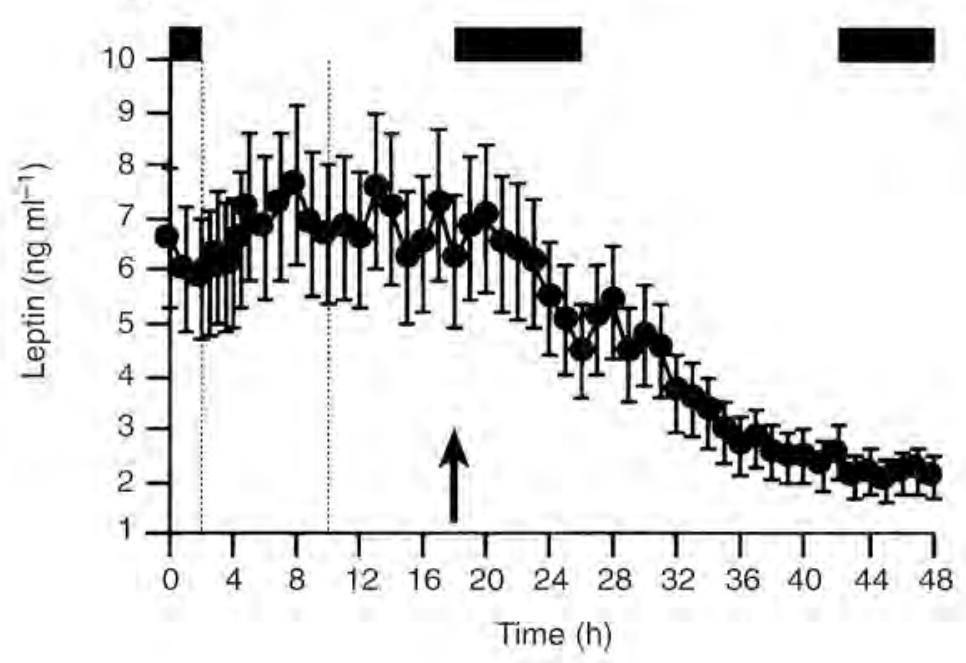

(b)

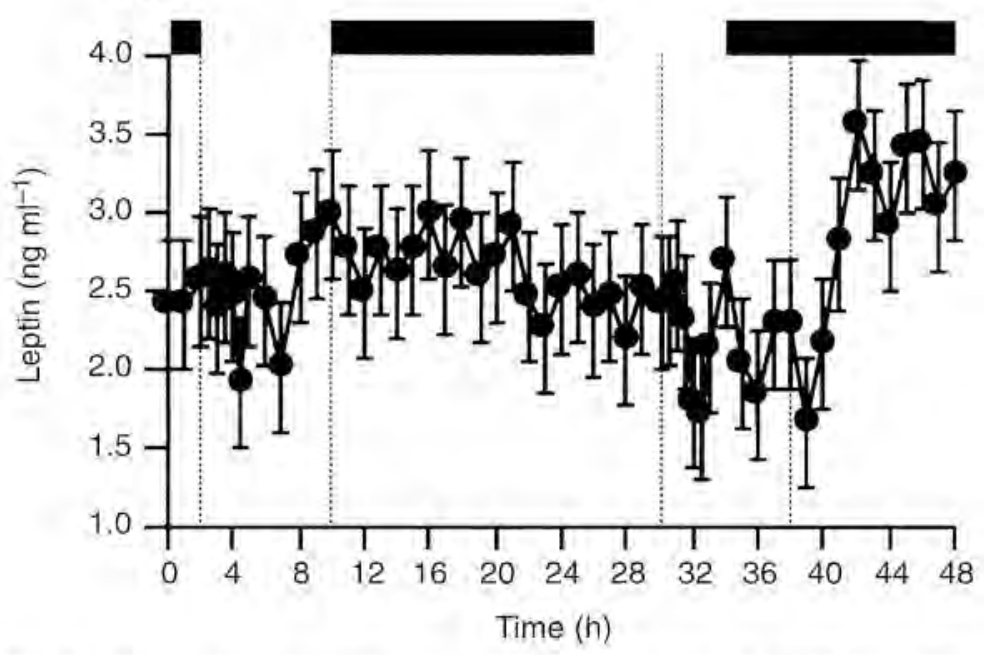

Fig. 1. Plasma leptin profiles over $48 \mathrm{~h}$ from sheep fed ad libitum, illustrating higher concentrations of leptin after 16 weeks in (a) sheep subjected to long-day rather than (b) short-day artificial photoperiods (note scale difference), and influence of meal times (vertical lines) and food deprivation (after vertical arrow in (a)). Solid horizontal bars indicate the periods of darkness. (Data from Marie et al., 2001).

not serve simply as a basic lipostatic signal, as originally proposed, but rather it is a composite signal reflecting both long-term nutritional status and short-term metabolic changes.

\section{Nutritional regulation of GnRH-LH: mediation by leptin?}

Reproductive neuroendocrine function is clearly influenced by nutrition, and leptin is emerging as a potential mediator of this response. The potential role of leptin in the onset of 
puberty is of particular interest as this manifestation of the primary activation of the GnRH pulse generator relates closely to body size in lambs (Foster and Nagatani, 1999). Although studies of temporal changes in endogenous leptin in sheep during puberty have not been performed, the assumption is made that larger, fatter, pubertal lambs have higher circulating leptin concentrations than do smaller, thinner lambs of the same age that remain prepubertal. However, in adult sheep, it is noteworthy that constantly higher versus lower adiposity is not stimulatory to $\mathrm{LH}$ (Rhind et al., 1989) and not to GnRH by inference given the close temporal relationship between them (Clarke and Cummins, 1982). Archer et al. (2002a) repeated this observation in steroid-replaced castrates and found that plasma leptin concentrations were higher in fatter (body condition score 3, scale 0-5) than in thinner (body condition score 2) sheep. This finding indicates that relatively high leptin concentrations per se do not stimulate $\mathrm{GnRH}-\mathrm{LH}$. However, increased food intake is stimulatory to GnRH-LH ('flushing') (Rhind et al., 1985) and concomitantly increases circulating leptin (Blache et al., 2000b; Archer et al., 2002a). Archer et al. (2002a) found that although the magnitude of the leptin signal was similar in constantly fatter sheep and in sheep with increased food intake, GnRH-LH was stimulated only in the latter scenario. This finding implies that the reproductive neuroendocrine axis can detect an acute increase in nutritional status, perhaps mediated by changes in the leptin signal. Conversely, an acute fall in circulating leptin in response to fasting in sheep (Marie et al., 2001; Adam et al., 2002) is associated with a decrease in LH pulse frequency (Nagatani et al., 2000), indicating that the reproductive neuroendocrine axis may also be able to detect acute decreases in nutritional status, perhaps mediated by leptin.

The foregoing correlative data are challenged by the apparent anomalies shown in the seasonal (photoperiod) cycles of sheep. Plasma leptin concentrations are higher in sheep subjected to long- rather than short-day photoperiods (Bocquier et al., 1998; Marie et al., 2001), yet sheep are reproductively active in short- but not in long-day photoperiods. Higher $\mathrm{LH}$ pulse frequencies have been measured in freely feeding rams exposed to short-day rather than long-day photoperiods, but higher plasma leptin was found in sheep subjected to longday rather than to short-day photoperiods (C. L. Adam, P. A. Findlay and Z. A. Archer, unpublished). Thus, a high leptin signal does not override photoperiodic inhibition of the reproductive neuroendocrine axis in long days, and likewise low leptin in freely feeding sheep does not inhibit the photoperiodic drive to the reproductive neuroendocrine axis in short days. Therefore, it is surmised that, with photoperiod providing the main drive to seasonal reproductive changes, leptin serves as a permissive threshold nutritional signal that is normally exceeded in satiated animals subjected to short-day photoperiods.

In the above scenarios of altered nutritional status, other metabolic hormones, notably insulin, are also affected and the observed responses cannot be attributed to leptin alone. Therefore, specific responses to leptin are assessed by exogenous administration experiments, although interaction with other metabolic cues cannot be ruled out.

\section{Effects of leptin administration}

The role of reduced leptin in fasting-induced suppression of $\mathrm{LH}$ was powerfully demonstrated by the restoration of pulsatile $\mathrm{LH}$ secretion in fasted adult sheep by s.c. injections of leptin (Nagatani et al., 2000). However, in a preliminary report, the same treatment administered to well-nourished lambs at puberty produced a variable response, and LH pulse frequency was stimulated only in lambs that had already initiated LH pulses at the start of leptin treatment (Jackson et al., 2001). Furthermore, an i.v, infusion of leptin for 10 days which increased plasma concentrations ninefold in prepubertal lambs did not stimulate LH pulsatility (Morrison et al., 2002), Therefore, leptin is unlikely to be a metabolic trigger for puberty, but can stimulate 
GnRH once the pulse generator has been activated (by another mechanism) and provides a permissive threshold for GnRH output in adults.

Leptin has many peripheral metabolic effects that could potentially influence the GnRH-LH response to peripheral leptin administration. Therefore, the specificity of the actions of leptin within the hypothalamus has been addressed in sheep by central (i.c.v.) administration studies conducted by four independent research groups. As the classic i.c.v, action of leptin in rodents is to decrease appetite drive, actions on both appetite and reproductive neuroendocrine output have been recorded in studies in sheep. The variable results from these administration studies have been summarized (Table 1) and a systematic appraisal of these findings provides information on the actions of leptin on these two important physiological axes. Although the different administration studies used different recombinant peptides, this was thought unlikely to explain the different responses observed (Table 1). Ovine, bovine and human leptins show as much as 95-99\% similarity in amino acid sequence (Dyer et al., 1997a) and human and ovine recombinant leptins show similar biological activity in vitro in stimulating BAF/3 cells transfected with the human leptin receptor (Gertler et al, 1998).

An i.c.v. infusion of leptin reduced food intake but did not affect LH secretion in ovariectomized ewes fed ad libitum, and restored $\mathrm{LH}$ secretion in food-restricted ovariectomized ewes without affecting food intake (Henry et al., 1999, 2001a). Morrison et al. (2001) too found that central leptin infusion reduced food intake in adequately nourished, but not in food-restricted ovariectomized, ewes, but no effect on LH secretion was observed in either group. Both groups carried out their studies in short days, either in natural photoperiod (Henry et al, 1999, 2001a) or artificial photoperiod (Morrison et al, 2001) (Table 1). A plausible reason for the different response might be the different dose rate of leptin used, which was lower in the studies by Henry et al. (1999, 2001a) (Table 1). Meanwhile, a third research group found that central leptin administration decreased both food intake and $\mathrm{LH}$ secretion in adequately nourished, intact rams that were fed a maintenance diet (Blache et al., 2000c) (Table 1). The first two research groups carried out their studies in gonadectomized sheep with no gonadal steroid replacement and the different $\mathrm{LH}$ response reported by Blache et al. (2000c) may have been due to the presence of gonadal steroids. In addition, although the infusion dose rate of Blache et al. (2000c) was similar to that of Henry et al. (2001a), it was administered for 5 days rather than 3 days allowing time for a secondary effect of the decreased food intake to reduce $\mathrm{L}$. $\mathrm{H}$ output. This interpretation was confirmed by the inclusion of a group of rams pair-fed to the leptin-infused rams which also had reduced $\mathrm{LH}$ (Blache et al., 2000c).

The previous studies had failed to demonstrate GnRH-LH stimulation by i.c.v. administration of leptin in adequately fed sheep, but had shown the ability of leptin to restore GnRH-LH secretion in undernourished, and presumably leptin-deficient, animals. Although experimental conditions differed in these studies, they all used i.c.v. infusion and the different leptin dosages were all in the 'pharmacological' range. However, in two contrasting paradigms, LH stimulation was observed in adequately fed steroid-replaced castrates in response to either a single 'pharmacological' i.c.v. injection of leptin or a 'physiological' i.c.v. leptin infusion (Miller et al., 2002). The 'physiological' infusion dose for sheep was calculated from known cerebrospinal fluid (CSF) turnover rates and accounted for CSF concentrations of leptin in sheep, which are about 0.3-1.2 $\mathrm{ng} \mathrm{ml}^{-1}$ (C. L. Adam and M. Marie, unpublished using the assay of Marie et al., 2001). These values are about 10\% of those for plasma leptin, and are in agreement with findings by Blache et al. (2000a). The infusion rate $\left(8 \mathrm{ng} \mathrm{h}^{-1}\right)$ was several orders of magnitude lower than that used in the previous infusion studies $(0.04-$ $50.0 \mu \mathrm{g} \mathrm{h}^{-1}$ ) (Table 1). Such an infusion carried out in the spring specifically increased LH pulse frequency with no concomitant effect on appetite. However, a single 'pharmacological' 


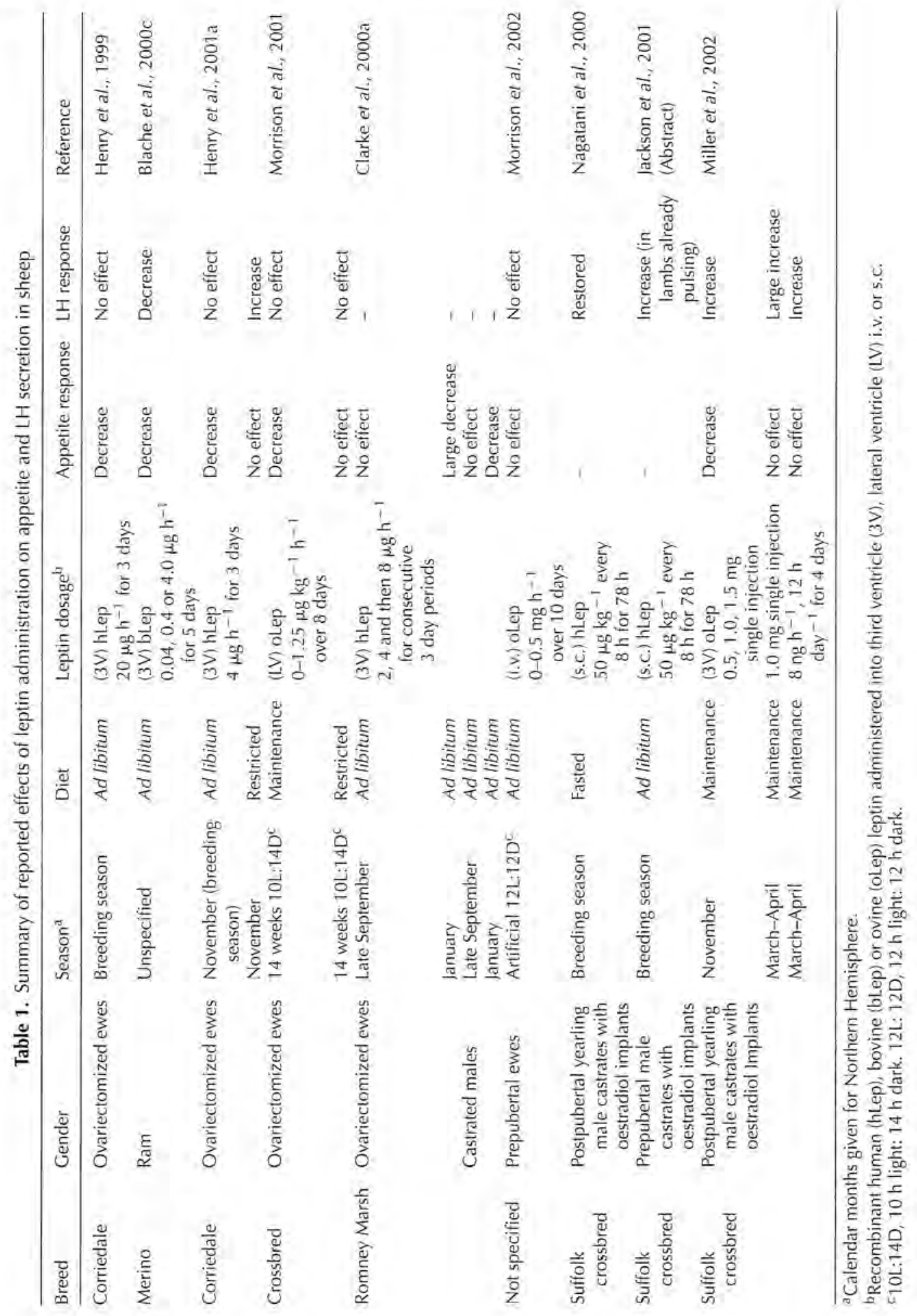


i.c.v. leptin injection at this time of year produced a surge-like release of LH (that is, increased pulse amplitude), which had no effect on appetite (Table 1). This finding highlights the difference in the nature of the $\mathrm{GnRH}-\mathrm{LH}$ response to 'physiological' rather than to 'pharmacological' administration.

Perhaps our most intriguing finding was that, unlike in the spring, the single pharmacological' i.c.v. leptin injection specifically stimulated LH pulse frequency (and decreased pulse amplitude) and simultaneously decreased appetite when applied to the same sheep in the late autumn (Miller et al, 2002) (Table 1, Fig. 2). This finding indicates that there are seasonal changes in sensitivity to leptin by both the appetite and reproductive neuroendocrine axes. Meanwhile, Clarke et al. (2000a) have also reported seasonal differences in sensitivity of the appetite axis to i.c.v. administration of leptin in sheep. In apparent contrast to our findings, their study with gonadectomized sheep (without steroid replacement) found that intake was inhibited by leptin infusion in the spring but not in the autumn. However, in both studies, the appetite-depressing effect of leptin was greatest at the time of year when the measured voluntary intake was at its lowest. The 'autumn' and 'spring' treatments in both studies equated to different calendar months (Table 1) and may not be strictly comparable, and the disparity may be resolved when such studies are conducted in controlled artificial photoperiods rather than in natural photoperiods. Nonetheless, it appears that the ovine hypothalamic appetite axis is more sensitive to inhibition by leptin in shorter days (late November in our study; January (Northern hemisphere equivalent) in Clarke et al., 2000a) than in longer days (MarchApril in our study; late September in Clarke et al., 2000a). This interpretation is supported by findings from studies of a seasonal rodent, the Siberian hamster. Similar to sheep, the Siberian hamster has increased circulating leptin in long days, when appetite and body weight increase, and decreased concentrations in short days, when appetite and body weight decrease (Atcha et al., 2000; Klingenspor et al., 2000). Relative leptin insensitivity in long days may be necessary to prevent the increased leptin concentrations causing reduced appetite and, thereby, counteracting the photoperiod-driven increases in intake and body weight. In support of this, loss of body weight induced by peripherally administered leptin in Siberian hamsters is apparently greater in short days than in long days (Atcha et al., 2000; Klingenspor et al., 2000).

A plausible explanation for the seasonal change in the nature or magnitude of the GnRH$\mathrm{LH}$ response to leptin is that photoperiod is the main cue for GnRH pulsatility in sheep, as discussed earlier with respect to endogenous leptin. Nutritional stimulation in the nonbreeding season (summer) cannot overcome photoperiodic inhibition of the reproductive neuroendocrine axis, but in the breeding season (autumn-winter) it can facilitate or increase GnRH output. Within the breeding season, receptivity to nutritional stimulation (mediated in part by leptin) varies with the photoperiod cycle with a greater response observed as the day lengths increase in spring, when photoperiod support is waning.

An additional sex difference in the appetite inhibition response to i.c.v. administration of leptin has been reported in sheep: gonadectomized females are apparently more sensitive than gonadectomized males (Clarke et al., 2000a). This higher sensitivity could relate to the normally higher systemic leptin signal in females than in males (Blache et al., 2000a; Ehrhardt et al., 2000), and sexual dimorphism may also exist in the reproductive neuroendocrine response to leptin, as observed in humans (Bouvattier et al., 1998). The role of gender and gonadal steroids in the GnRH response to leptin in sheep has yet to be resolved.

Overall, the assorted leptin administration trials in sheep have together provided invaluable information on the neuroendocrine feedback role of this hormone (Table 1). A repeated finding was a positive dose dependence of the appetite inhibition response (Blache et al., 2000c; Clarke et al., 2000a; Miller et al., 2002) across 'pharmacological' i.c.v. doses of leptin, 
(a)

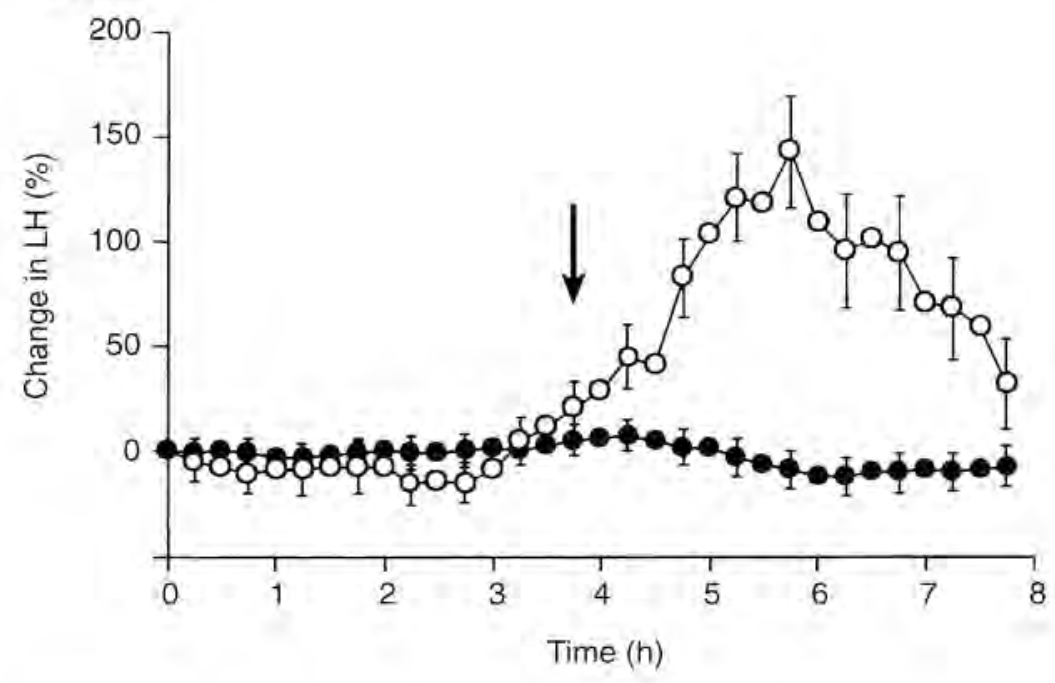

(b)

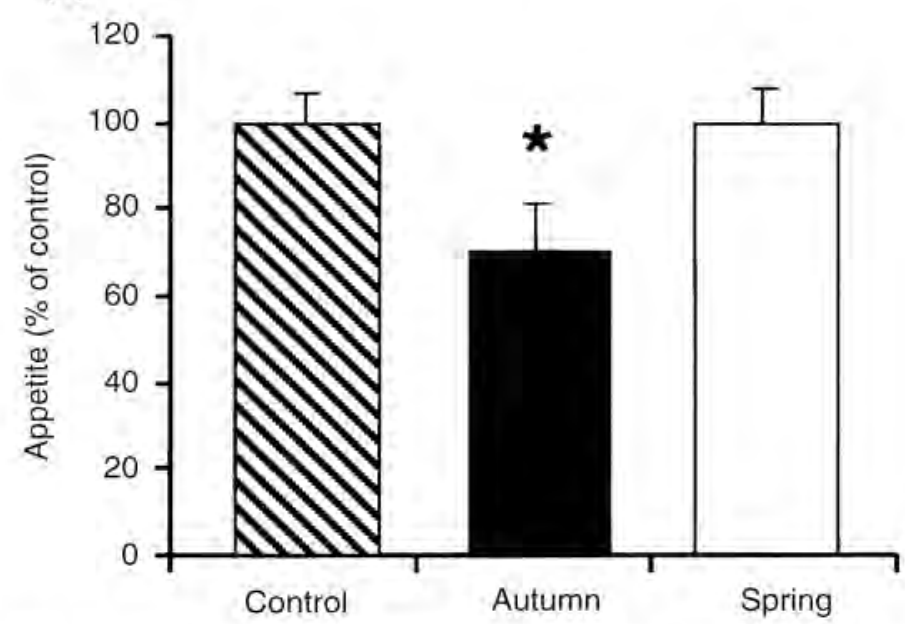

Fig. 2. (a) $\mathrm{LH}$ and (b) appetite responses in adequately nourished sheep to intracerebroventricular administration of leptin (vertical arrow) as a pharmacological single injection in the autumn (-) or the spring (O). Appetite was measured as the ad libitum intake during $2 \mathrm{~h}$ immediately after injection. *Autumn significantly different from spring and control measurements $(P<0.05)$. (Data from Miller et al., 2002).

with no evidence forthcoming that 'physiological' concentrations of leptin induce such a response. Therefore, it is questionable whether the appetite-inhibiting action of leptin plays a major physiological role in normal animals. Furthermore, in contrast to i.c.v. administration studies, increasing the concentration of circulating leptin in lambs by i.v. infusion had no effect on voluntary food intake in the study of Morrison et al. (2002). However, the seasonal dependence of the appetite response to i,c,v, administration of leptin reveals the ability of the hypothalamus to adjust sensitivity to leptin by mechanism(s) that could potentially 
be elucidated in photoperiod-entrained sheep. There was also seasonal dependence in the $\mathrm{GnRH}-\mathrm{LH}$ response, with the magnitude greater in spring than in autumn in contrast to the appetite response. This finding strongly indicates that responses to leptin by the two axes are mediated by distinct mechanisms. Considering all of the studies, there is apparent negative dose dependence of the $\mathrm{LH}$ pulsatile response; thus, in contrast to the appetite response, a modest increase in intracerebral leptin appears more stimulatory to the frequency of $\mathrm{GnRH}$ pulses than is a large increase in leptin. Large increases in leptin induced a surge-like release of $\mathrm{LH}$, had no effect, or caused a secondary inhibition of $\mathrm{LH}$ through food intake inhibition. These administration studies by different groups with different sheep models have also indicated a potential role of gonadal steroids, as leptin-stimulated $\mathrm{GnRH}-\mathrm{LH}$ in adequately-fed sheep has been seen only in the presence of oestradiol (Miller et al, 2002). Therefore, oestradiol may be required to facilitate leptin actions in the brain, as appears to be the case for rodents (Kimura et al., 2002).

\section{Sites of leptin action: neuroendocrine target sites}

\section{Central leptin receptors}

Leptin exerts its actions by binding to and activating leptin receptors. Following on from the pioneering rodent studies, central leptin receptors were localized in the ovine hypothalamus by iodoleptin binding studies, in situ hybridization detection of gene expression and immunocytochemical detection of receptor protein (Dyer et al., 1997b; Gertler et al., 1998; Williams et al., 1999; Iqbal et al., 2001a), Specifically, the signalling form of the receptor $(\mathrm{OB}-\mathrm{Rb})$ is localized within the hypothalamus largely in the arcuate (ARC) and ventromedial $(\mathrm{VMH})$ nuclei, but also in the dorsomedial hypothalamic nucleus $(\mathrm{DMH})$, lateral hypothalamic region, and in the preoptic area (POA, Williams et al., 1999). In the ovine anterior pituitary gland, gene expression has been detected by RT-PCR (Dyer et al., 1997b), but not by in situ hybridization (Williams et al., 1999). However, immunoreactivity was reported to be widespread across all types of cell, including gonadotrophs (Iqbal et al, 2000); this extended to the pars tuberalis of the pituitary gland, where we have also found high gene expression (Z. A. Archer, P. A. Findlay and C. L. Adam, unpublished).

The leptin receptor is present in different isoforms arising from mRNA splice variants. The signalling form (OB-Rb) with its long intracellular domain is the predominant form in the hypothalamus, and this is the only form studied to date in the ruminant brain. However, although the systemic signal may reach regions of the ARC and mediobasal hypothalamus outside the blood brain barrier (BBB), it is assumed to some extent that leptin must also pass through the BBB or enter the CSF to act on its central targets. Short isoforms of the leptin receptor, present in the choroid plexus and neural capillaries, are implicated in transport of leptin into the brain (Ahima et al., 2000). It is thought to be a saturable process contributing to the development of 'leptin resistance' and obesity in humans, but this aspect has not been addressed in sheep. Interestingly, an interaction with another metabolic signalling hormone, insulin, has been demonstrated in sheep in which i.c.v. insulin infusion decreased the expression of hypothalamic OB-Rb (Daniel et al., 2000).

\section{Leptin-GnRH neuronal interaction}

Results from studies in vitro support a role for leptin in reproductive neuroendocrine regulation. Thus, leptin stimulates GnRH release from rat hypothalamic explants (Yu et al., 1997; Lebrethon et al., 2000) and from immortalized murine GnRH neurones (Magni et al., 1999). In support of the conclusions emerging from i.c.v. leptin administration studies 

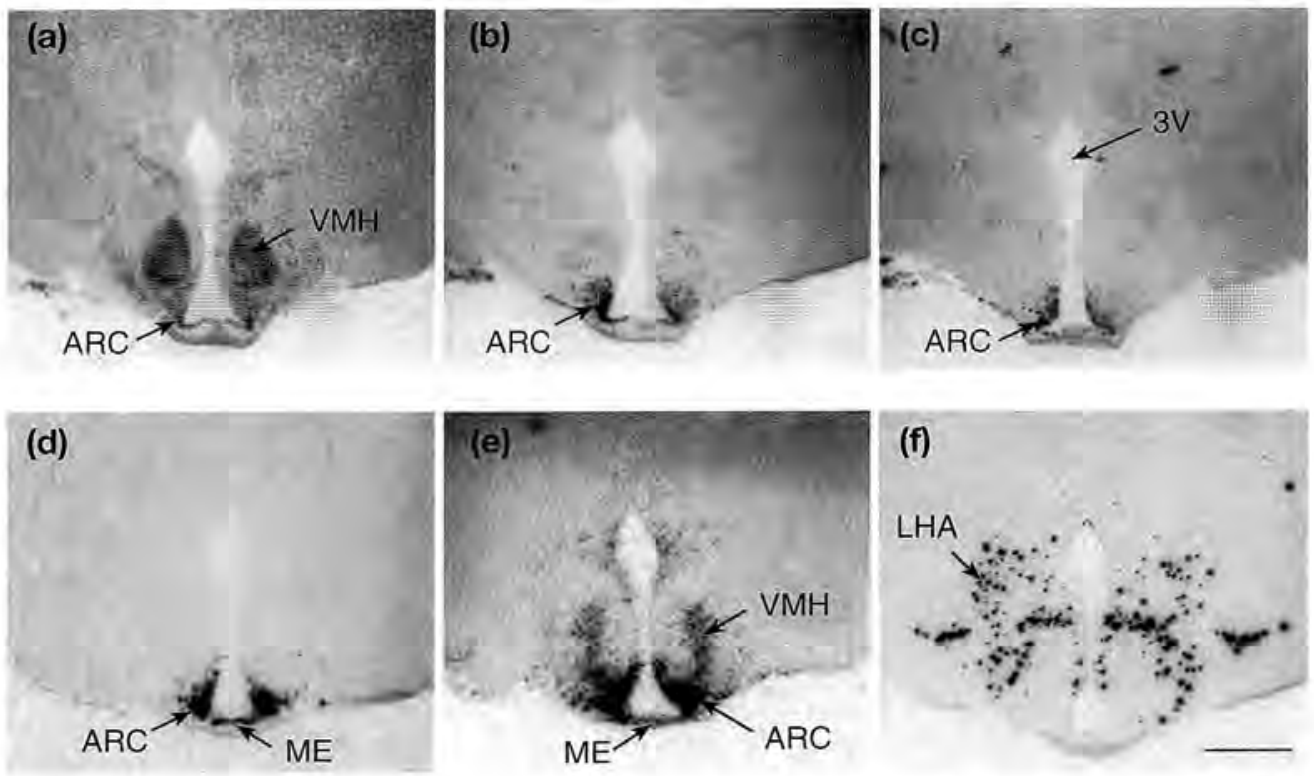

Fig. 3. Autoradiographs of gene expression for (a) leptin receptor $(\mathrm{OB}-\mathrm{Rb})$, (b) neuropeptide $Y$ (NPY), (c) agouti-related peptide (AGRP), (d) pro-opiomelanocortin (POMC), (e) cocaine- and amphetamine-regulated transcript (CART) and (f) orexin in adjacent sections through an ovine hypothalamus (from Adam et al., 2002). 3V: third ventricle; ARC: arcuate nucleus; LHA: lateral hypothalamic area; $\mathrm{ME}$ : median eminence; $\mathrm{VMH}$ : ventromedial hypothalamus. Scale bar represents $3.5 \mathrm{~mm}$.

in sheep described earlier, the responses in vitro were negatively related to leptin dose rate (Yu et al., 1997; Magni et al., 1999). However, although leptin receptors have been identified in immortalized GnRH cells derived from mice (Magni et al., 1999), they were not found in GnRH neurones of monkeys (mRNA, Finn et al., 1998) or rats (immunoreactivity, Hakansson et al., 1998). No co-localizations have been reported in sheep, but OB-Rb gene expression is seen in the POA in which GnRH cell bodies are also found (Williams et al., 1999). Nonetheless, it is likely that leptin may not act directly on GnRH neurones but via intermediary neurones to evoke the response. In addition, direct effects at the pituitary gland are possible as leptin can stimulate LH release from rat pituitary explants (Yu et al., 1997) and leptin receptor immunoreactivity has been detected in ovine pituitary gonadotrophs (Iqbal et al., 2000).

\section{Neuropeptide targets}

The actions of leptin on appetite and energy balance are transduced by neuronal populations within the ARC that express the leptin receptor, notably neuropeptide Y (NPY)/agoutirelated peptide (AGRP) and pro-opiomelanocortin (POMC)/cocaine- and amphetamineregulated transcript (CART) neurones (Ahima et al., 2000). These neuropeptides may also be implicated in transducing leptin actions on $\mathrm{GnRH}$. Gene expression for these neuropeptides, and their sensitivity to negative energy balance, has been confirmed in the ovine ARC (Adam et al., 2002) (Fig. 3). Co-expression of OB-Rb and NPY has been demonstrated in sheep (Williams et al., 1999), i.c.v. leptin reduced NPY gene expression in ovariectomized ewes (Henry et al., 1999) and i.c.v. administration of NPY inhibited GnRH in sheep (McShane 
et al., 1992). There is good anatomical evidence in sheep that NPY neurones contact GnRH neurones (Tillet et al., 1989) and, furthermore, we have shown that nutritionally 'flushed', lupin-fed rams with increased pulsatile LH secretion have reduced NPY gene expression in the ARC (D. Blache and C. L. Adam, unpublished). It is therefore possible that leptin stimulates GnRH by removing inhibition by NPY.

AGRP is downregulated by leptin, thereby contributing to the anorexigenic response to leptin in laboratory species (Ahima et al, 2000). Apart from a study in rats demonstrating GnRH stimulation by AGRP (Stanley et al., 1999), there is little evidence to link AGRP with the $\mathrm{G} n \mathrm{RH}$ response to leptin. AGRP gene expression in the ARC was reduced in fat compared with thin sheep in studies by Henry et al. (2001b) and Archer et al. (2002a). In the latter study, circulating leptin was higher in fatter than thinner sheep but there was no difference in LH output. AGRP acts to antagonize hypothalamic actions of the melanocortins produced from the POMC precursor, and the role of the melanocortin system in reproduction has been reviewed by Schioth and Watanobe (2002). The putative involvement of melanocortins in mediating actions of leptin on GnRH in sheep remains speculative. Differences in POMC gene expression in the ARC have not been found between sheep of differential adiposity (Henry et al., 2000, Archer et al., 2002a), but neither are there differences in LH secretion in these animals (Archer et al., 2002a).

Leptin upregulation of CART may be a mechanism for leptin stimulation of GnRH in rodent models (Lebrethron et al., 2000), and anatomical evidence indicates close apposition between CART and GnRH neurones (Leslie et al., 2001). In support of this mechanism in sheep, we have found increased CART gene expression in the ARC of nutritionally flushed, lupin-fed rams with high circulating leptin and stimulated $\mathrm{GnRH}-\mathrm{LH}$ output (D. Blache and C. L. Adam, unpublished). However, conversely, CART gene expression was increased in the ARC of fat sheep with high leptin compared with thin sheep with low leptin, without correlated differences in LH (Archer et al., 2002a).

Recently, a novel mechanism has been proposed by which orexin could be involved in regulation of $\mathrm{GnRH}$ by leptin. Orexin gene expression is localized in the lateral hypothalamus (Fig. 3). Orexin neurones were shown to express leptin receptor immunoreactivity in sheep, and retrograde labelling showed a subpopulation of orexin cells projecting to the POA where GnRH cell bodies reside (lqbal et al, 2001b). In addition, orexin administered i.c.v. stimulated $\mathrm{LH}$ secretion in rams (Blache et al., 2002). However, no difference in hypothalamic orexin gene expression was found in nutritionally flushed rams with increased circulating leptin and stimulated LH output (D. Blache and C. L. Adam, unpublished).

The observation of seasonal differences in response to i.c.v. leptin administration indicates that there may be an interaction between leptin and photoperiod (melatonin) signalling. Receptors for melatonin and leptin have not been co-localized, yet their presence has been independently reported in similar hypothalamic regions, such as $\mathrm{VMH}$ (Chabot et al., 1998 and Dyer et al, 1997b, respectively) and DMH (Morgan and Mercer, 2001 and Williams et al., 1999, respectively) and, intriguingly, in the pars tuberalis (PT) of the pituitary gland (Morgan and Mercer, 2001; Z. A. Archer, P. A. Findlay and C. L. Adam, unpublished, respectively). Although this finding may provide potential anatomical evidence for direct interactions between melatonin and leptin, it is perhaps more likely that the interaction lies downstream, with photoperiod (melatonin) altering the sensitivity of neuronal targets for leptin. Evidence for seasonally altered expression of leptin-sensitive hypothalamic pathways in sheep is emerging. No effect of photoperiod on OB-Rb and NPY gene expression has been found in the ARC of steroid-implanted castrates (Archer et al., 1999) or rams (C. L. Adam, P. A. Findlay and Z. A. Archer, unpublished); however, Clarke et al. (2000b) report seasonal changes in natural photoperiod for NPY gene expression in the ARC of ovariectomized ewes. Steroid-implanted 


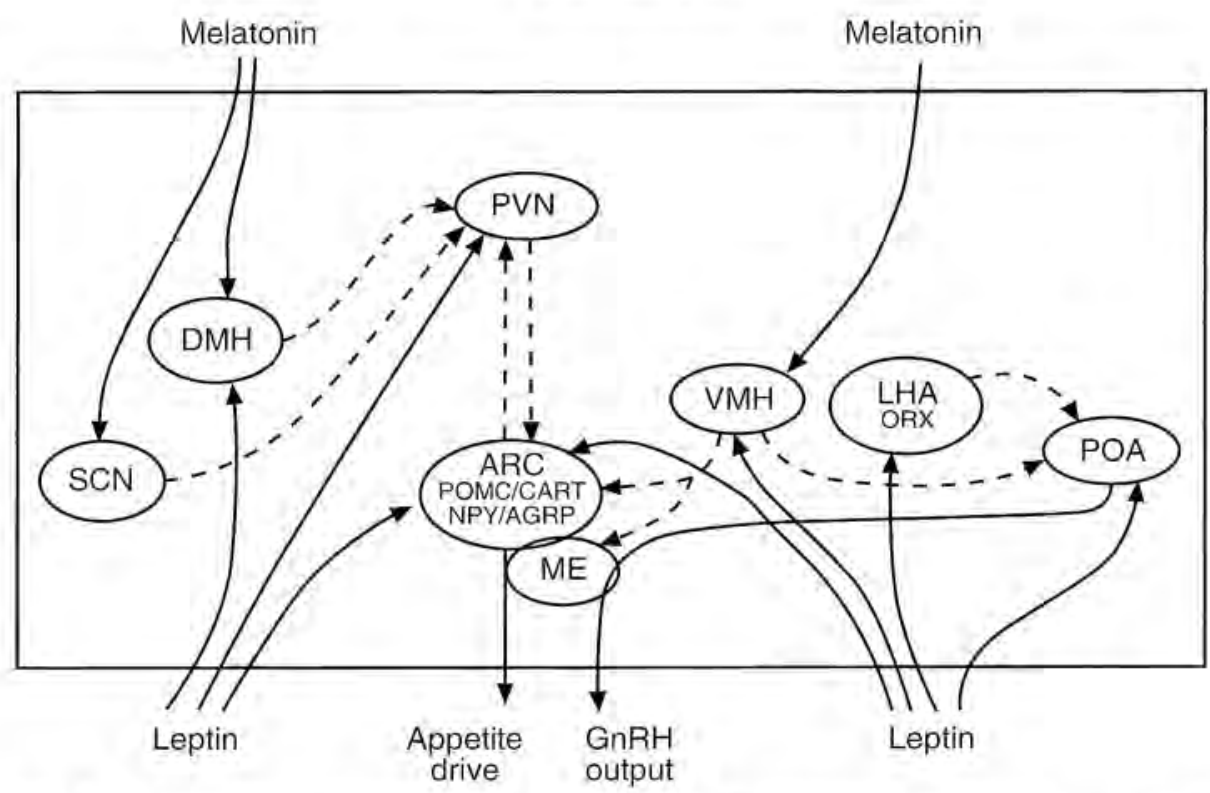

Fig. 4. Hypothetical schema showing potential brain pathways in sheep for interaction between photoperiod (melatonin) and leptin feedback on the appetite axis (left-hand side) and on GnRH output (right-hand side). The phenotype of neurones expressing melatonin receptors in the suprachiasmatic nucleus $(\mathrm{SCN})$, dorsomedial hypothalamus $(\mathrm{DMH})$ and ventromedial hypothalamus $(\mathrm{VMH})$ is unknown. Likewise, the identity of the critical neurones expressing leptin receptors in the $\mathrm{DMH}, \mathrm{VMH}$, paraventricular hypothalamic nucleus (PVN) and preoptic area (POA) is unknown. However, leptin is known to act on neuropeptide Y (NPY)/agouti-related peptide (AGRP) and pro-opiomelanocortin $(\mathrm{POMC}) /$ cocaine- and amphetamine-regulated transcript (CART) neurones in the arcuate nucleus (ARC), and on orexin (ORX) neurones in the lateral hypothalamic area (LHA), There are key neuronal projections from the SCN, DMH and ARC to the PVN, a critical regulatory centre for appetite control, through which melatonin and leptin feedback may thereby be coordinated. Acute actions of leptin on GnRH release at the median eminence (ME) may be mediated by neurones in the ARC, such as NPY neurones. Furthermore, photoperiod-sensitive actions of leptin on GnRH may be mediated via ORX neurones in the LHA projecting to GnRH cell bodies in the POA, or via unidentified interneurones in the $\mathrm{VMH}$ or POA projecting to $\mathrm{GnRH}$ neurones.

castrates show upregulated hypothalamic orexin gene expression in short days (Archer et al., 2002b), whereas rams show downregulated orexin in short days (C. L. Adam, P. A. Findlay and Z. A. Archer, unpublished). However, rams subjected to short-day photoperiods show upregulated POMC and CART and downregulated AGRP gene expression compared with rams subjected to long-day photoperiods (C. L. Adam, P. A. Findlay and Z. A. Archer, unpublished). These data are consistent with increased activity of melanocortin and CART pathways in short-day photoperiods, but it is open to speculation as to whether these changes contribute to the increased hypothalamic sensitivity to leptin in short-day photoperiods.

\section{Conclusion}

Leptin is clearly implicated in communicating nutritional status to the reproductive neuroendocrine axis in sheep. In permissive photoperiod, a low systemic leptin signal inhibits 
GnRH-LH, and a threshold level acts permissively for normal GnRH pulsatile output. Leptin does not trigger $\mathrm{GnRH}$ pulsatility but within the brain an acute increase in leptin can increase pulse frequency or pulse amplitude during the breeding season; however, chronically high leptin concentration is not stimulatory. Leptin also decreases appetite. The magnitude of (stimulatory) $\mathrm{GnRH}-\mathrm{LH}$ and (inhibitory) appetite responses is differentially influenced by the time of year, indicating interaction with photoperiod (melatonin) and distinct mechanisms of leptin action on the two axes (Fig. 4). Interaction with other nutritional or metabolic cues within the brain is also highly probable. The GnRH response seems to be negatively dosedependent and the appetite response positively dose-dependent. Unresolved issues include the impact of gender and gonadal steroids on central actions of leptin, transport into the brain and neural pathways of leptin action. The differential seasonal and dose sensitivity of the two axes challenges the assumption that neural mechanisms are shared between appetite and $\mathrm{GnRH}$ axes. Although orexigenic and anorexigenic leptin targets in the hypothalamus are well characterized, mediators of leptin actions on $\mathrm{GnRH}$ are not known. It is proposed that photoperiod-entrained sheep may provide a useful model to elucidate the distinct mechanisms.

Work undertaken by the authors described in this review was supported by the Scottish Executive En-. vironment and Rural Affairs Department. The authors are grateful to A. Gertler of the Hebrew University of Jerusalem for the gift of ovine recombinant leptin.

\section{References}

Adam CL, Archer ZA, Findlay PA, Thomas L and Marie $M$ (2002) Hypothalamic gene expression in sheep for cocaine-and amphetamine-regulated transcript, proopiomelanocortin, neuropeptide $\mathrm{Y}$, agouti-related peptide and leptin receptor, and responses to negative energy balance Neuroendocrinology 75250 256

Ahima RS, Saper CB, Klier JS and Elmquist JK (2000) Leptin regulation of neuroendocrine systems Frontiers of Neuroendocrinology 21 263-307

Archer ZA, Rhind SM, Findlay PA, McMillen S and Adam CL (1999) Effects of food restriction and photoperiod on gonadotrophin secretion and hypothalamic NPY and POMC gene expression in castrate male sheep Journal of Reproduction and Fertility $A b$ stract Series 2357

Archer ZA, Rhind SM, Findlay PA, Kyle CE, Thomas L, Marie M and Adam CL (2002a) Contrasting effects of different levels of food intake and adiposity on LH secretion and hypothalamic gene expression in sheep Journal of Endocrinology 175 383-393

Archer ZA, Findlay PA, Rhind SM, Mercer JG and Adam CL (2002b) Orexin gene expression and regulation by photoperiod in the sheep hypothalamus Regulatory Peptides 104 41-45

Atcha Z, Cagampang FR, Stirland JA, Morris ID, Brooks AN, Ebling FJ, Klingenspor $M$ and Loudon AS (2000) Leptin acts on metabolism in a photoperioddependent manner, but has no effect on reproductive function in the seasonally breeding Siberian hamster (Phodopus sungorus) Endocrinology 1414128 4135
Blache D, Tellam R, Chagas LM, Blackberry MA, Vercoe PV and Martin GB (2000a) Level of nutrition affects leptin concentrations in plasma and cerebrospinal fluid in sheep Journal of Endocrinology $165625-637$

Blache D, Chagas LM, Blackberry MA, Vercoe PE and Martin GB (2000b) Metabolic factors affecting the reproductive axis in male sheep Journal of Reproduction and Fertility 120 1-11

Blache D, Celi P, Blackberry MA, Dynes RA and Martin GB (2000c) Decrease in voluntary feed intake and pulsatile $\mathrm{LH}$ secretion after intracerebroventricular infusion of recombinant bovine leptin in mature male sheep Reproduction, Fertility and Development 12 373-381

Blache D, Adam CL and Martin GB (2002) The mature male sheep: a model to study the effects of nutrition on the reproductive axis Reproduction Supplement 59219-233

Bocquier F, Bonnet M, Faulconnier Y, Guerre-Millo $M$, Martin P and Chilliard Y (1998) Effects of photoperiod and feeding level on perirenal adipose tissue metabolic activity and leptin synthesis in the ovariectomized ewe Reproduction, Nutrition and Development $38489-498$

Bouvattier C, Lahlou N, Roger M and Bougneres P (1998) Hyperleptinaemia is associated with impaired gonadotrophin response to $\mathrm{GnRH}$ during late puberty in obese girls, not boys European Journal of Endocrinology 138 653-658

Chabot V, Caldani $M$, de Reviers $M M$ and Pelletier I (1998) Localization and quantification of melatonin receptors in the diencephalon and posterior 
telencephalon of the sheep brain Journal of Pineal Research 24 50-57

Chilliard $\mathrm{Y}$, Bonnet $\mathrm{M}$, Delavaud $\mathrm{C}$, Faulconnier $\mathrm{Y}$, Leroux C, Djiane J and Bocquier F (2001) Leptin in ruminants. Gene expression in adipose tissue and mammary gland, and regulation of plasma concentration Domestic Animal Endocrinology 21 271-295

Clarke IJ and Cummins IT (1982) The temporal relationship between gonadotropin-releasing hormone $(\mathrm{G} n \mathrm{RH})$ and luteinizing hormone in ovariectomized ewes Endocrinology 111 1737-1739

Clarke IJ, Tilbrook AJ, Turner AI, Doughton BW and Goding IW (2000a) Sex, fat and the tilt of the earth: effects of sex and season on the feeding response to centrally administered leptin in sheep Endocrinology $1422725-2728$

Clarke IJ, Scott CI, Rao A, Pompolo S and Barker-Gibb ML (2000b) Seasonal changes in the expression of neuropeptide $Y$ and pro-opiomelanocortin mRNA in the arcuate nucleus of the oyariectomized ewe; relationship to the seasonal appetite and breeding cycles Journal of Neuroendocrinology 12 1105-1111

Daniel JA, Thomas MG, Hale CS, Simmons JM and Keisler DH (2000) Effect of cerebroventricular infusion of insulin and (or) glucose on hypothalamic expression of leptin receptor and pituitary secretion of $\mathrm{LH}$ in diet-restricted ewes Biochemical and Biophysical Research Communications 18 177-185

Daniel JA, Whitlock BK, Baker JA, Steele B, Morrison CD, Keisler DH and Sartin JL (2002) Effect of body fat mass and nutritional status on 24-hour leptin profiles in ewes Journal of Animal Science 80 1083-1089

Delavaud C, Bocquier F, Chilliard Y, Keisler DH, Gertler A and Kann G (2000) Plasma leptin determination in ruminants: effects of nutritional status and body fatness on plasma leptin concentration assessed by a specific RIA in sheep Journal of Endocrinology 165 519-526

Delavaud C, Daveau A, Tourret M, Malpaux B and Chilliard Y (2002) Absence of plasma leptin or metabolite variation after subcutaneous melatonin release in adult ewes Proceedings of the British Society for Animal Science 200290 (Abstract)

Dyer CJ, Simmons IM, Matteri RL and Keisler DH (1997a) cDNA cloning and tissue-specific gene expression of ovine leptin, NPY-Y1 receptor and NPYY2 receptor Domestic Animal Endocrinology 14 295-303

Dyer CJ, Simmons JM, Matteri RL and Keisler DH (1997b) Leptin receptor mRNA is expressed in ewe anterior pituitary and adipose tissues and is differentially expressed in hypothalamic regions of wellfed and feed-restricted ewes Domestic Animal Endocrinology 14 119-128

Ehrhardt RA, Slepetis RM, Siegal-Willott I, Van Amburgh ME, Bell AW and Boisclair YR (2000) Development of a specific radioimmunoassay to measure physiological changes of circulating leptin in cattle and sheep Journal of Endocrinology 166519 528

Finn PD, Cunningham MJ, Pau KY, Spies HG, Clifton DK and Steiner RA (1998) The stimulatory effect of leptin on the neuroendocrine reproductive axis of the monkey Endocrinology $1394652-4662$

Foster DL and Nagatani S (1999) Physiological perspectives on leptin as a regulator of reproduction: role in timing puberty Biology of Reproduction $60205-$ 215

Gertler A, Simmons J and Keisler DH (1998) Large-scale preparation of biologically active recombinant ovine obese protein (leptin) FEBS Letters 422 137-140

Hakansson ML, Brown LH, Ghilardi N, Skoda RC and Meister B (1998) Leptin receptor immunoreactivity in chemically defined target neurons of the hypothalamus Journal of Neuroscience 18 559-572

Henry BA, Goding JW, Alexander WS, Tilbrook AJ, Canny BJ, Dunshea F, Rao A, Mansell A and Clarke I) (1999) Central administration of leptin to ovariectomized ewes inhibits food intake without affecting the secretion of hormones from the pituitary gland: evidence for a dissociation of effects on appetite and neuroendocrine function Endocrinology 140 1175- 1182

Henry BA, Tilbrook AJ, Dunshea FR, Rao A, Blache D, Martin GB and Clarke IJ (2000) Long-term alterations in adiposity affect the expression of melanin concentrating hormone and enkephalin but not proopiomelanocortin in the hypothalamus of ovariectomized ewes Endocrinology 141 1506-1514

Henry BA, Goding JW, Tilbrook AJ, Dunshea FR and Clarke IJ (2001a) Intraventricular infusion of leptin elevates the secretion of luteinizing hormone without affecting food intake in long-term food restricted sheep, but increases growth hormone irrespective of bodyweight Journal of Endocrinology 168 67-77

Henry BA, Rao A, Ikenasio BA, Mountjoy KG, Tilbrook AJ and Clarke IJ (2001b) Differential expression of cocaine-and amphetamine-regulated transcript and agouti related-protein in chronically food-restricted sheep Brain Research $\mathbf{9 1 8}$ 40-50

Iqbal J, Pompolo S, Considine RV and Clarke IJ (2000) Localization of leptin receptor-like immunoreactivity in the corticotropes, somatotropes and gonadotropes in the ovine anterior pituitary Endocrinology 141 1515-1520

Iqbal J, Pompolo S, Murakami T, Grouzmann E, Sakurai T, Meister B and Clarke IJ (2001a) Immunocytochemical characterization of localization of long-form leptin receptor (OB-Rb) in neurochemically defined cells in the ovine hypothalamus Brain Research 920 55-64

Iqbal J, Pompolo S, Sakurai T and Clarke IJ (2001b) Evid ence that orexin-containing neurones provide direct input to gonadotropin-releasing hormone neurones in the ovine hypothalamus Journal of Neuroendocrinology 13 1033-1041 
Jackson L, Jaffe C, Pelt J and Foster D (2001) Leptin regulation of $\mathrm{LH}$ secretion in prepubertal sheep Biology of Reproduction 64 Supplement 1189 (Abstract)

Keisler DH, Daniel JA and Morrison CD (1998) The role of leptin in nutritional status and reproductive function Journal of Reproduction and Fertility Supplement 54 425-435

Kimura M, Irahara M, Yasui T, Saito S, Tezuka M, Yamano S, Kamada M and Aono T (2002) The obesity in bilateral ovariectomized rats is related to a decrease in the expression of leptin receptors in the brain Biochemical and Biophysical Research Communications 290 1349-1353

Klingenspor M, Niggemann $\mathrm{H}$ and Heldmaier G (2000) Modulation of leptin sensitivity by short photoperiod acclimation in the Djungarian hamster, Phodopus sungorus. Journal of Comparative Physiology $\mathbf{1 7 0}$ $37-43$

Lebrethon MC, Vandersmissen E, Gerard A, Parent AS and Bourguignon JP (2000) Cocaine- and amphetamine-regulated-transcript peptide mediation of leptin stimulatory effect on the rat gonadotropin-releasing hormone pulse generator in vitro. Journal of Neuroendocrinology 12 383-385

Leslie RA, Sanders S], Anderson SI, Schuhler S, Horan TL and Ebling FJ (2001) Appositions between cocaine and amphetamine-related transcript- and gonadotropin releasing hormone-immunoreactive neurons in the hypothalamus of the Siberian hamster Neuroscience Letters 314 111-114

McShane TM, May T, Miner JL and Keisler DH (1992) Central actions of neuropeptide-Y may provide a neuromodulatory link between nutrition and reproduction Biology of Reproduction 46 1151-1157

Magni P, Vettor R, Pagano C, Calcagno A, Beretta $E$, Messi E, Zanisi M, Martini L and Motta M (1999) Expression of a leptin receptor in immortalized GnRH-secreting neurons Endocrinology $1401581-$ 1585

Marie M, Findlay PA, Thomas L and Adam CL (2001) Daily patterns of plasma leptin in sheep: effects of photoperiod and food intake Journal of Endocrinology $170277-286$

Miller DW, Findlay PA, Morrison MA, Raver N and Adam CL (2002) Seasonal and dose-dependent effects of intracerebroventricular leptin on luteinising hormone secretion and appetite in sheep Journal of Endocrinology 175 393-404

Morgan PJ and Mercer JG (2001) The regulation of body weight: lessons from the seasonal animal Proceedings of the Nutrition Society $60127-134$
Morrison CD, Daniel JA, Holmberg BJ, Djiane J, Raver N, Gertler A and Keisler DH (2001) Central infusion of leptin into well-fed and undernourished ewe lambs: effects on feed intake and serum concentra. tions of growth hormone and luteinizing hormone Journal of Endocrinology 141 1464-1469

Morrison CD, Wood R, McFadin EL, Whitley NC and Keisler DH (2002) Effect of intravenous infusion of recombinant ovine leptin on feed intake and serum concentrations of $\mathrm{GH}, \mathrm{LH}$, insulin, IGF-1, cortisol and thyroxine in growing prepubertal ewe lambs Domestic Animal Endocrinology 22 103-112

Nagatani S, Zeng Y, Keisler DH, Foster DL and Jaffe CA (2000) Leptin regulates pulsatile luteinizing hormone and growth hormone secretion in the sheep Endocrinology 141 3965-3975

Rhind SM, Leslie ID, Gunn RG and Doney IM (1985) Plasma $\mathrm{FSH}_{\text {, }} \mathrm{LH}$ and prolactin and progesterone profiles of Cheviot ewes with different levels of intake before and after mating, and associated effects on reproductive performance Animal Reproduction Science 8 301-313

Rhind SM, McMillen S, McKelvey WAC, RodriguezHerrejon FF and McNeilly AS (1989) Effects of the body condition of ewes on the secretion of $\mathrm{LH}$ and $\mathrm{FSH}$ and the pituitary response to gonadotrophinreleasing hormone Journal of Endocrinology $\mathbf{1 2 0}$ 497-502

Schioth HB and Watanobe $\mathrm{H}$ (2002) Melanocortins and reproduction Brain Research Brain Research Reviews $38340-350$

Stanley SA, Small CJ, Kim MS, Heath MM, Seal LJ, Russell SH, Ghatei MA and Bloom SR (1999) Agouti related peptide (AgRp) stimulates the hypothalamopituitary-gonadal axis in vivo and in vitro in male rats Endocrinology $1405459-5462$

Tillet $Y$, Caldani $M$ and Batailler $M$ (1989) Anatomical relationships of monoaminergic and neuropeptide $Y$ containing fibres with luteinizing hormone-releasing hormone systems in the preoptic area of the sheep brain: immunohistochemical studies Journal of Chemical Neuroanatomy 2 319-326

Williams LM, Adam CL, Mercer JG, Moar KM, Slater D, Hunter L, Findlay PA and Hoggard N (1999) Leptin receptor and neuropeptide $\mathrm{Y}$ gene expression in the sheep brain Journal of Neuroendocrinology 11 165169

Yu WH, Kimura $M$, Walczewska A, Karanth S and McCann SM (1997) Role of leptin in hypothalamicpituitary function Proceedings National Academy of Science USA 94 1023-1028 